\title{
Studies in the regulation of uterine activity
}

\author{
D. G. PORTER \\ M.Sc., Ph.D., B.Vet.Med., M.R.C.V.S. \\ Department of Physiology, Royal Veterinary College, London, N.W.1
}

IN 1956, Csapo put forward the theory of the local action of placental progesterone in an attempt to explain the separate delivery of human twins, several weeks apart. This theory, which holds that progesterone from the placenta can reach the overlying myometrium by a direct route and produce a functional asymmetry of the uterus, has been criticised (Short, 1960) on the ground that such progesterone would be absorbed by the maternal blood stream, and distributed uniformly to the myometrium, thus precluding an asymmetric effect. In order to determine whether progesterone absorbed from an intrauterine site is distributed asymmetrically, we chose the bicornuate uterus as an experimental model, since one horn could be used as a control for the other in the same animal. Finger-cot balloons were inserted into each uterine horn of ovariectomized non-pregnant rabbits. A perforated catheter accompanied each balloon, permitting the introduction of progesterone into the uterine lumen. After the animals had recovered from surgery, the balloons in each horn were filled to an equal volume with water. This volume varied among the rabbits between 2 and $10 \mathrm{ml}$ depending upon the size of the uterus. In each case a final volume was selected which produced a high activity with a resting pressure of not more than $10 \mathrm{mmHg}$. Progesterone in sesame oil was injected into the lumen of the experimental horn, and sesame oil alone into the control horn. Intra-uterine pressure was monitored before, during and after progesterone treatment. Although both horns underwent a loss of active intra-uterine pressure, the loss was significantly greater $(P<0.025)$ and recovery significantly prolonged, in the horns treated with progesterone. When the technique was applied to pregnant animals, it was possible to induce unilateral deliveries (Porter, 1968). In four rabbits thus treated, the control horns delivered a total of twelve out of fourteen foetuses before the first foetus was delivered from the treated horns.

These results can best be explained on the basis that some progesterone reached the myometrium of the treated horn by a direct route, not involving the systemic circulation, and in sufficient quantity to produce a significant difference in the mechanical activity of the two horns. The anatomical basis of ${ }_{\sigma}^{\omega}$ this direct route is not known. These results support the feasibility of the 'local placental progesterone' 3 . hypothesis since if progesterone from an oil droplet in the uterine lumen can pass through the endo- or metrium to the uterine muscle, it would be expected $\overrightarrow{0}$ that steroids secreted by the placenta, which is more intimately related to the myometrium, would also pass directly.

Zarrow, Anderson \& Callantine (1963) and $\vec{c}$ Schofield (1964) have reported failure to prolong pregnancy in the guinea-pig with systemically administered progestogens. In view of the 'local' theory of placental progesterone, and the fact thgt $\vec{\bullet}$ the placenta of the guinea-pig is known to secrefe progesterone (Heap \& Deanesly, 1966), locill application of progesterone, or medroxyproges-0 terone acetate (Depo-Provera, Upjohn) to the uterus of the pregnant guinea-pig, might be expected to prolong pregnancy, where intra-muscular injec-요 tions failed. Accordingly, pregnant guinea-pigs were $\stackrel{\varrho}{\rightarrow}$

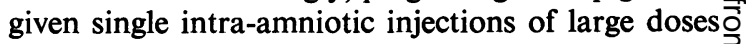
of progesterone or medroxyprogesterone acetate (MAP), some 5 or 6 days before term. The results are shown in Table 1.

TABLE 1. The effect of progesterone and medroxy-proges terone acetate (MAP) upon pregnancy in the guinea-pig

\begin{tabular}{|c|c|c|c|}
\hline Substance & $\begin{array}{c}\text { Dose/uterine } \\
\text { horn (mg) }\end{array}$ & $\begin{array}{l}\text { Day of } \\
\text { injection }\end{array}$ & $\begin{array}{l}\text { Day of } \\
\text { delivery }\end{array}$ \\
\hline Progesterone & $\begin{array}{r}50 \\
400 \\
500\end{array}$ & $\begin{array}{l}63 \\
64 \\
63\end{array}$ & $\begin{array}{l}71 \\
70 \\
69\end{array}$ \\
\hline MAP & $\begin{array}{l}125 \\
125 \\
125\end{array}$ & $\begin{array}{l}64 \\
64 \\
64\end{array}$ & $\begin{array}{l}67 \\
66 \\
67\end{array}$ \\
\hline
\end{tabular}

Although these experiments are incomplete, it iso interesting that even with very high doses of either progesterone or MAP, pregnancy was not prolonged. These failures are difficult to explain, since it seems unlikely that the doses were too low, or that there定 
had been inadequate absorption. Possible explanations are that progesterone metabolism is altered in late pregnancy in the guinea-pig, for which there is already some evidence (Heap \& Deanesly, 1967), or that the guinea-pig produces an antagonist to progesterone at term. A further possibility is that progesterone is not an important factor in the maintenance of pregnancy in the guinea-pig.

The mechanism by which intra-amniotic treatment with hypertonic saline induces abortion in women is disputed (see Csapo, 1966; Fuchs, 1967 for reviews). Accordingly, experiments were designed to study this problem in rabbits. In order to determine the effect of hypertonic saline upon myometrial activity, without the complicating factors of its effect upon the foetus and placenta, saline was instilled into the uterine lumen of non-pregnant rabbits, while the intra-uterine pressure was monitored. This treatment was rapidly followed by an increase in uterine activity which subsided within $1 \mathrm{hr}$. This finding is in agreement with the earlier report of Wagner (1966). Furthermore, the response was confined to one horn, since no significant change in intra-uterine pressure occurred in the untreated control horn. The effect was probably not due to an increase in the volume of fluid in the uterine lumen, since the cervices of all eight animals studied were patent, thus permitting the expulsion of any fluid which accumulated. In view of the rapidity of the onset of the effect and its short duration, it was concluded that the response was due to a 'direct' effect of saline upon the uterine muscle. No similar response could be evoked by the injection of normal saline or in animals which had been treated $18 \mathrm{hr}$ previously with $5 \mathrm{mg}$ of progesterone.

Following the injection of $3.5 \mathrm{ml}$ of $20 \%$ sodium chloride into the amniotic sacs of fourteen pregnant rabbits (26/27 day), nine aborted within $56 \mathrm{hr}$ of treatment on average. Recordings of intra-uterine pressure revealed a transitory increase in active pressure of low amplitude immediately after treatment, but no significant increases were recorded until some 24 hr later (Porter, Becker \& Csapo, 1968). All the aborted foetuses were dead and their average weight was $26 \mathrm{~g}$, indicating that they had died shortly after treatment.

The five rabbits which failed to abort maintained their pregnancies to term, and each delivered at least one living foetus. It would seem that in these animals one or more amniotic sac had been overlooked at surgery and had not been injected with the hypertonic saline. These results suggested that the abortions might be attributable to foetal death, but when the umbilical cords of all foetuses in five rabbits were severed, thus ensuring death of the foetuses, pregnancies were maintained almost to term (102 hr after treatment on average).
The time course of the abortions, and the nature of the uterine activity which preceded them, differed markedly from the very brief activity produced by hypertonic saline in the non-pregnant animal. Thus, it seemed unlikely that the abortions were due to a 'direct' effect of hypertonic saline upon the myometrium, a conclusion that was supported by the failure of five out of fourteen animals receiving comparable doses of saline to abort. Nevertheless, we tested the correctness of this assumption by administering $3.5 \mathrm{ml}$ of $20 \% \mathrm{NaCl}$ per conceptus, extra-amniotically by means of an indwelling catheter inserted between the foetal membranes and the endometrium throughout the length of the uterine horn. This technique deposited the saline in contact with the endometrium, thus simulating the treatment of the non-pregnant animals. None of the six animals in this group aborted, and all delivered at least some living foetuses at term.

Histological examination of the placentae taken from animals $24 \mathrm{hr}$ after intra-amniotic injection of hypertonic saline, revealed structural damage. The tissue had undergone a marked loss of basophilia, connective tissue spaces were expanded, and nuclei were karyorrhetic. These observations suggested that the abortions might be due to placental damage. When total destruction of the placentae was caused by manual dislocation, abortions followed promptly, in $31 \mathrm{hr}$ on average. The time difference of 31 and $56 \mathrm{hr}$ in the placental dislocation and intra-amniotic hypertonic saline treatment groups was probably attributable to the difference in the amount of damage caused by these procedures to the placentae. The probability that the abortions following placental dislocation were due to luteal failure was supported by the fact that they could be prevented by the daily administration of oestrogen, a substance known to be luteotrophic in the rabbit (Westman \& Jacobsohn, 1937; Robson, 1939; Keyes \& Nalbandov, 1967). This was further supported by the fact that oestrogen treatment was ineffective if the ovaries were removed when the placentae were dislocated.

In order to test the hypothesis that the abortions following intra-amniotic injection of hypertonic saline were due to placental damage, six rabbits were given daily injections of oestrogen $(25 \mu \mathrm{g}$ oestradiol daily) following saline treatment. All these animals maintained their pregnancies to term.

We concluded, therefore, that the abortions probably resulted from the interruption of placental luteotrophic function, so that where one or more placentae escaped damage, pregnancy was maintained.

In women, the ovaries are essential only during the early part of pregnancy; thereafter, the placenta secretes progesterone. It is known that the 
intra-amniotic injection of hypertonic saline in women causes structural damage to the placenta (Straus, 1963; Christie et al., 1966). Csapo (1966) has claimed that such damage impairs placental endocrine function, with the result that progesterone output falls and abortion ensues. Although in the rabbit, the maintenance of pregnancy is not dependent upon placental progesterone, it is dependent upon another placental endocrine factor, a luteotrophin, which is essential for the continued elaboration of progesterone by the corpus luteum. It is significant, therefore, that the only procedures which produced abortions in the rabbits of the present series, were those which damaged all the placentae and thereby impaired the endocrine function of these organs. This was so, despite the fact that, unlike the situation in women, the source of progesterone was located outside the uterus. Thus it seems probable that the mechanism underlying saline abortions in the two species is similar.

\section{References}

Christie, J.L., Anderson, A.B., Turnbull, A.C. \& Beck, J.S. (1966) The human placenta and membranes: a histological and immunofluorescent study of the effects of intra-amniotic injection of hypertonic saline. J. Obstet. Gynaec. Brit. Cmwlth, 73, 399.

Csapo, A.I. (1956) Progesterone 'block'. Amer. J. Anat. 98, 273.

CsAPO, A.I. (1966) The termination of pregnancy by the intra-amniotic injection of hypertonic saline. Greenhill's Yearbook in Obstetrics.
Fuchs, F. (1967) Termination of pregnancy by intra气 amniotic injection of hypertonic solutions. Advances i Obstetrics and Gynecology (Ed. by S. L. Marcus and C. C尺 Marcus), Chapter 19, Vol. 1. Williams \& Wilkins, Baltic more.

Heap, B. \& Deanesly, R. (1966) Progesterone in systemi blood and placentae of intact and ovariectomized guinea pigs. J. Endocr. 34, 417.

Heap, B. \& DeANesly, R. (1967) The increase in plasm progesterone levels in the pregnant guinea-pig and it $\overline{s p}$ possible significance. J. Reprod. Fert. 14, 339.

KeYes, P.L. \& Nalbandov, A.V. (1967) Maintenance and function of corpora lutea in rabbits depend on estrogenos Endocrinology, 80, 938.

PORTER, D.G. (1968) The local effect of intra-uterine pro우 gesterone treatment on myometrial activity in rabbits. J. Reprod. Fert. 15, 437.

Porter, D.G., BeCKer, R. \& CsaPo, A.I. (1968) On the mechanism of action of intra-amniotic hypertonic saline treatment in rabbits. J. Reprod. Fert. 17, 433.

RoBSON, J.M. (1939) Maintenance of pregnancy in thẹ. hypophysectomized rabbit by the administration of oestrin. J. Physiol. (Lond.), 95, 83.

SCHOFIELD, B.M. (1964) Myometrial activity in the pregnante guinea-pig. J. Endocr. 30, 347.

Straus, L. (1963) Report in: Initiation of Labor. Publi Health Service Conference, Princeton, New Jersey.

SHORT, R.V. (1960) Blood progesterone levels in relation to parturition. J. Reprod. Fert. 1, 61.

WAGNER, G. (1966) Changes in myometrial activity following intra-uterine injection of hypertonic saline. J. Reprod Fert. 12, 405.

Westman, A. \& Jacobsohn, D. (1937) Uber Oestrin $=$ Wirkungen auf die Corpus-luteum-Funktion. Acta obsges gynec. scand. 17, 1.

Zarrow, M.X., Anderson, N.C. \& Callantine, M (1963) Failure of progestogens to prolong pregnancy the guinea-pig. Nature (Lond.), 198, 690. 